\title{
Corrective Osteotomy and Volar Locking Plate for Multi-planar Mal-United Distal Radius Fractures, Improving Function or Just Restoring Anatomy?
}

\author{
Amr Elkhouly ${ }^{1 *}$, Taher Yousry ${ }^{2}$ and Neloy Roy ${ }^{3}$ \\ ${ }^{1}$ Senior fellow Orthopaedics, Southampton University Hospital, UK \\ ${ }^{2}$ Senior registrar, Royal National Orthopaedic Hospital, UK \\ ${ }^{3}$ Senior consultant, Hull Royal Infirmary, UK
}

Submission: April 26, 2017; Published: May 09, 2017

*Corresponding author: Amr ElKhouly, Senior fellow Orthopaedics, Southampton University Hospital, UK, Tel: 447780 281299; Email: amrelkhouly@gmail.com

\begin{abstract}
Introduction: Malunion remains one of the most common complications after conservative treatment of extra-articular distal radius fractures. Many different methods have been proposed for correction of such malunions; however, precise correction of a symptomatic malunion requires simultaneous correction of displacement, angulation, and rotation in multiple planes.
\end{abstract}

Objective: The aim of this retrospective study is to assess the functional and radiological outcome of multi planar corrective osteotomy , distraction and locking fixed angle volar plate with bone grafting as the standard treatment of distal radius malunions requiring multi planar correction.

Methods: We conducted a retrospective study on 15 patients- 4 males, 11 females. Mean age of 49- ranging from 17 to 68 . All patients underwent volar approach, open wedge distraction osteotomy and fixation with locking fixed angle volar plate and cancellous bone grafting Radiographic measurements and functional assessments were taken preoperatively, 3,6months and one year postoperatively Radiological measurements included radial height, tilt, inclination and ulnar variance. Functional assessment included flexion/extension arc, range of supination and pronation, grip and pinch strength, DASH and SF12 scores.

Results: Time to surgery from the original fracture was 17.4 months (range from 8 to 36 months). Number of patients with malunion of dominant hand was 39\%. Mean follow-up was 16.4 months (range from 6 to 45 months). Osteotomies healed at an average of 11.3 weeks with one case of delayed union that healed at 24 weeks without further intervention. All radiographic measurements improved postoperatively, eleven out of the fifteen patients had an average of $18.84 \hat{\mathrm{A}}^{\circ}$ of dorsal tilt (range between $6 \hat{\mathrm{A}}^{\circ}$ and $30 \hat{\mathrm{A}}^{\circ}$ ) which was corrected to an average of $9.17 \hat{\mathrm{A}}^{\circ}$ volar tilt. Ulna variance was pre-operatively positive in all patients with an average of $2.6 \mathrm{~mm}$ (ranging between $1.2 \mathrm{and} 5.1 \mathrm{~mm}$ ) which was corrected postoperatively to less than one $(0.96 \mathrm{~mm})$, three patients had radial angulations of $20.6 \hat{\mathrm{A}}^{\circ}$ on average, which was fully corrected postoperatively. Flexion-extension arc improved with significant difference compared to figures prior to surgery and so was the grip and pinch strength The average DASH and SF12 scores have shown figures comparative to the normal population post deformity correction Complications included one case of low grade wound infection requiring oral antibiotic and another patient suffered from loss of sensation along the distribution of the anterior cutaneous nerve of the thigh related to the bone graft donor site.

Conclusion: Corrective multiplanar osteotomy with distraction and fixed angle plate fixation device resulted in improvement of distal radius anatomy, functional outcome and improvement of pain score. In this study we aim to describe technique and functional outcome of corrective osteotomy for malunion of distal radial fractures.

\section{Perspective}

Despite advances in technqiues of internal fixation, malunion remains the most common complication after distal radius fractures [1,2] whether intra or extra articular. With overall malunion rates reaching up to $17 \%$ [3]. Although the severity of the deformity does not always dictate surgical intervention $[4,5]$ patients with malunion can experience significant disability in the form of pain, arthritis,reduced range of motion, decreased grip strength and visible deformity [6,7] all related to loss of normal volar tilt,radial inclination and radial height relative to the ulna [8-10].

There is no defined cut off point to the degree of deformity that warrants surgical correction, it was proven that increased deformity correlates with increased dysfunction [11] Fernandez recommended corrective osteotomy when the degree of angulation in the sagittal plane is greater than 25 to $30[12,13]$. However, grip strength was proven to be reduced with an 


\section{Orthopedics and Rheumatology Open Access Journal}

angulation of more than 20o [14] and it was shown that patients with less than 20 o of deformity who are symptomatic might benefit from surgery [9].

Biomechanical studies have shown the impact of the deformity on the wrist joint on different levels, the deformity disturbs the normal wrist contact pressures predisposing to wrist arthritis [15-17], mere loss of radial height and dorsal angulation increases contact pressures through the ulna [1]. Normally $82 \%$ of axial load of the wrist joint is transmitted through the radius, while an ulna positive variant of $2.5 \mathrm{~mm}$ or more increases axial load across the ulna to $42 \%[18,19]$. This increased load may lead to problems of the TFCC if not arthrosis in the whole wrist joint [20]. With reduced radial height and radio ulnar mismatch, distal radio-ulnar joint incongruity causes instability, reduced motion and arthrosis in the DRUJ [21,22].

Malunion may lead to compensatory motion of the carpus, where dorsally angulated malunions may well present with adaptive instability in the form of DISI (dorsal Intercalary segment instability) [1]. Corrective osteotomy of the distal radius is considered the foundation of treatment of malunion [23]. although simple deformities in the sagittal or coronal planes do not pose surgical problems for the orthopaedic surgeon [2], multiple studies have shown that the majority of distal radius fracture malunion have more than one plane deformity $[24,25]$ which does indeed present a surgical challenge for correction because of the complex anatomic deformity often associated with such a condition, such complexity together with the variations in the type of malunion, and the inherent technical challenges of its surgical correction are all reflected by the numerous different techniques that have been described to date as a means of correction [26,27], the common factor between these techniques depended on accurate correction with a positive correlation between accurate anatomic correction and eventual overall wrist function, these techniques have shown not only to improve radiographic parameters, but more importantly improve motion, pain and grip strength [28,29].

Fernandez described the traditional open wedge osteotomy, bone grafting and dorsal plating for dorsally angulated malunions [12], although this technique improves function and relieves pain dorsal plating is associated with frequent morbidities [3032], hardware prominence and extensor tendon irritation or rupture being the most common [1]. Open wedge osteotomies also presented a few reported disadvantages including increased instability at the osteotomy site before complete healing [33,34], increased risk of implant failure or non union resulting from axial loading and shear stresses associated with early wrist mobilization [34,35] and the complication at the bone graft donor site $[35,36]$.

Volar locking plates arrived recently to the scene yet have established their role in the treatment of distal radius fractures $[36,37]$ the inherent strength of the final construct allowing for early motion of the wrist joint and early return to function as well as low morbidities related to the volar approach $[37,38]$, have made the use of external fixator and dorsal plating in acute fractures far less common. Because of such qualities, the senior author started using this technique for correction of malunions of the distal radius.

\section{Objective}

The purpose of the study was to assess the outcome of corrective osteotomy, bone grafting and volar locking plate in treating multiple plane deformities of the distal radius fracture malunion, outcome measures included physical and radiographic examination, DASH, MAYO and SF12 scores, as well as grip and pinch strength

\section{Material and Methods}

This is a retrospective study including patients who were operated consecutively by the senior author using the same volar locking plate system opening wedge osteotomy and iliac crest bone grafting from 2006 to 2011. Inclusion criteria included patients with radial sided pain, more than one plane deformity, resulting from a malunited fracture of the distal radius. We were able to identify 15 patients who fitted the criteria and after committee approval we contacted the patients and had approval of 13 patients out of the 15 to be included the remaining two were unreachable even through their GP, we were able to collect the physical and radiological examination for all 15 patients from the medical records, we were able to collect outcome scores from all 13 patients, 9 patients underwent the grip strength test using the Jamar Dynamometer whilst 4 did not agree to undergo the test.

Demographic data including age, sex, hand dominance, occupation, type of initial management of the fracture, interval between the injury and surgery were all recorded. Range of movement of the wrist joint was recorded for both extremities pre and postoperatively for flexion-extension as well as supination-pronation. Preoperative and postoperative radiographic measurements of volar tilt, radial inclination and ulnar variance were obtained. Operative details including the approach, type of fixation, type of bone graft, time to union of the osteotomy site, complication and subsequent surgical procedures were all recorded.

\section{Outcome Scores}

The severity of the pain was assessed using Visual analogue score before and after surgery with a value of 0 to 10 with 0 being no pain and 10 being agonizing pain. The SF12 is a measure of health related quality of life, consisting of 12 questions relating to physical health, function, pain and emotional health. Scores range from 0 to 100 with higher scores defining a more favourable state of health. Mean Scores were compared pre and postoperatively as well as with the general average UK population. The DASH score is for self-assessment of residual disability of the upper limb, it consists of thirty items 21 of which address the ability to perform certain functions and nine address symptoms. Mean score was compared pre and 


\section{Orthopedics and Rheumatology Open Access Journal}

postoperatively with the score ranging from 0 to 100 with higher scores indicating higher disability.

The Mayo score allows for a total count of 100 points in four categories, residual pain, functional range of movement, return to work and grip strength, with 100 representing normal wrist function, average figures were compared prior to surgery and during the last postoperative outpatient visit. Grip and pinch strength was recorded during the last outpatient visit as the best value of three trials with the use of a Jamar Dynamometer and compared with the opposite side.

\section{Surgical Technique}

A volar approach to the distal radius extending proximally from the wrist crease along the flexor carpi radialis tendon using a $5-7 \mathrm{cms}$ incision, the radial artery identified and protected radially with pronator quadrates elevated along its radial and distal borders and the brachioradialis partially released from its insertion, the volar locking plate of the acumed set was used in all cases (standard size), where the distal end of the plate was aligned with the wrist joint, with the aid of $\mathrm{k}$ wires passing through the joint as well as under fluoroscopic image control to align the plate with the required volar tilt and radial inclination, once achieved the distal locking screws were applied. This was followed by the osteotmy being performed as close as possible to the level of deformity, and parallel to the wrist joint, once performed, the radius is pulled out to length with the aid of a laminar spreader applied at the osteotmy site and a cortical screw placed proximally to give the counter pressure required to regain the required radial height and ulna variance. Once corrected the plate was held in place and the first proximal screw was drilled through the oval hole to allow for further fine tuning followed by application of proximal locking screws through the rest of the plate holes (pictures), this was followed by cancellous bone graft harvesting from the same side iliac crest and the amount taken depending on the gap required to be filled at the osteotomy site, cortical bone graft was not added in any of the procedures, the pronator quadratus was brought back to its original position and the subcutaneous layer and skin were sutured using absorbable sutures. All patients had a below elbow well padded splint and discharged the same or the following day to surgery (Figures 1-4).

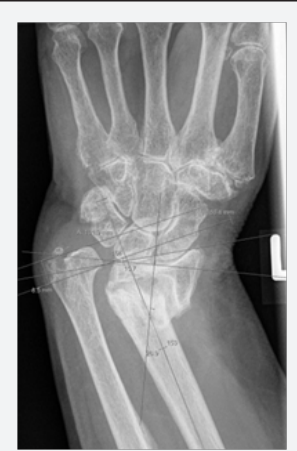

Figure 1: Preoperative planning to verify the amount and direction of the deformity.

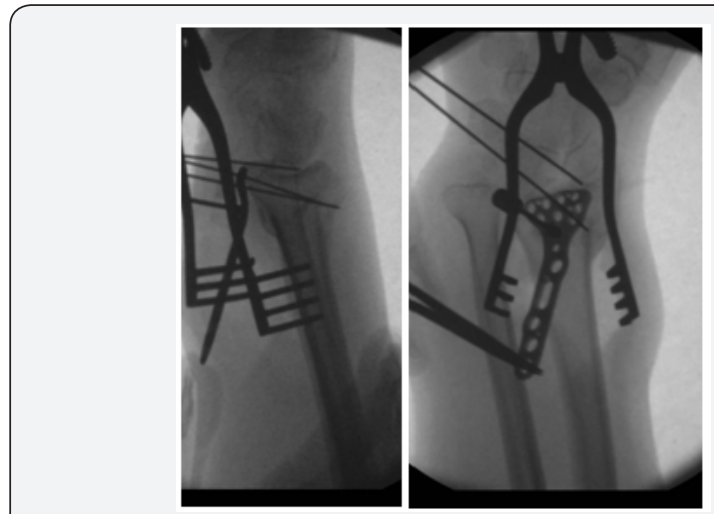

Figure 2: Plate positioned to restore radial inclination and tilt and referenced to wrist joint using an intra-articular $\mathrm{K}$ wire.

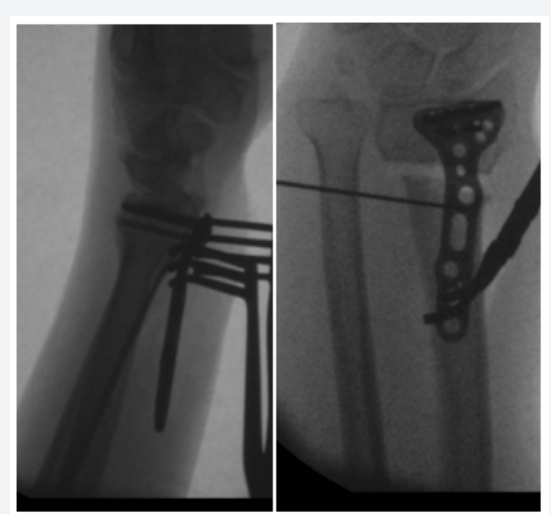

Figure 3: Distal locking screws applied parallel to wrist joint. Plate usually is off the bone proximally in keeping with the deformity. Osteotomy performed just proximal to DRUJ to maintain joint integrity.

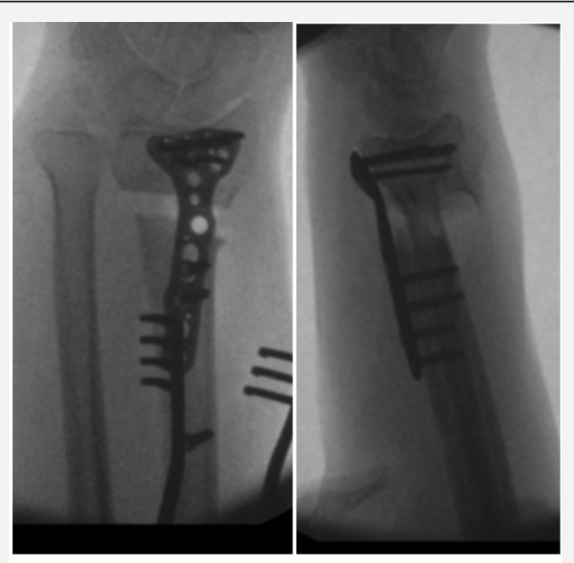

Figure 4: The distal fragment and plate jacked up to required height by the aid of a laminar spreader. Proximal screws applied to maintain the position. The gap is filled with autologous cancellous bone graft.

\section{Results}

The study included 11 female and 4 male patients, with a mean age of 46 (17-70), 4 patients had their injury in the dominant side, 11 patients were treated initially conservatively (cast application), 2 patients with Manipulation under 
anaesthesia and $\mathrm{K}$ wire fixation and 2 patients with open reduction and plate fixation. Average time to surgery was 17.5 months (range, 8-36), one patient had an associated Extensor pollicis longus rupture related to her original fracture which was surgically treated at a later stage, and another patient suffered from signs and symptoms of carpal tunnel syndrome which was managed surgically during the same sitting.

\section{Radiographic Outcomes}

11 patients had a dorsal tilt of $19^{\circ}$ on average (range $6^{\circ}-23^{\circ}$ ) which was corrected to an average of $9^{\circ}$ of volar tilt, 4 patients had an excessive volar tilt of $26^{\circ}[24,26,28]$ which was corrected to an average of $11^{\circ}$ of volar tilt. All 15 patients had a positive ulna variance of $2.5 \mathrm{~mm}$ on average (range 1.5-5.1) which was corrected in all patients to less than $1 \mathrm{~mm}$ (average of 0.96 ). Three patients had a valgus angulation of $20.6^{\circ}$ on average, which was corrected to neutral (Table 1).

Table 1: Deformities of patients.

\begin{tabular}{|c|c|c|c|}
\hline Deformity & Patients & Preop & Postop \\
\hline Dorsal tilt & 11 & $-19^{\circ}$ & $+9^{\circ}$ \\
\hline Volar tilt & 4 & $\left(6^{\circ}-23^{\circ}\right)$ & $+26^{\circ}$ \\
\hline Ulna variance & 15 & $(24-28)$ & $+11^{\circ}$ \\
\hline $\begin{array}{c}\text { Radial } \\
\text { angulation }\end{array}$ & 3 & $20.6 \mathrm{~mm}$ & $\begin{array}{c}\text { Less than } \\
1 \mathrm{~mm}(0.96)\end{array}$ \\
\hline & & $(1.5-5.1)$ & Neutral \\
\hline
\end{tabular}

\section{Clinical Outcomes}

Wrist flexion extension improved significantly postoperatively $(\mathrm{p}<0.05)$, with mean flexion improving from $46.4^{\circ}$ preoperatively to $75.7^{\circ}$ on average ( $p$ value 0.001 ), palmar flexion also improved from an average of $34.6^{\circ}$ to $63.6^{\circ}$ post correction ( $p$ value 0.001 ), as for the DRUJ, supination showed significant improvement from an average of $78.2^{\circ}$ before surgery to $85^{\circ}$ post deformity correction ( $p$ value 0.039 ), however pronation did not show significant improvement with a mere change of $86.4^{\circ}$ to $87.8^{\circ}$ on average ( $p$ value 0.317 ) (Table 2).

Table 2: Type of Movement ( $\left.{ }^{*} p<0.05\right)$.

\begin{tabular}{|c|c|c|c|}
\hline Type of Movement & Preoperative & postoperative & P value* \\
\hline Dorsi-flexion & $46.4^{\circ}$ & $75.7^{\circ}$ & 0.001 \\
\hline & $(+/-13.6)$ & $(+/-18.2)$ & \\
\hline Palmar-flexion & $34.6^{\circ}$ & $63.6^{\circ}$ & 0.001 \\
\hline Supination & $(+/-16.8)$ & $(+/-24)$ & \\
\hline Pronation & $\left(+/-18.2^{\circ}\right.$ & $85^{\circ}$ & 0.039 \\
\hline & $86.4^{\circ}$ & $(+/-10.2)$ & \\
\hline & $(+/-9.3)$ & $(+/-8.0)$ & 0.317 \\
\hline
\end{tabular}

\section{Outcome Scores}

Five out of the 15 patients could not be contacted despite extensive search by phone, sending letters as well as checking change of address/contact details through their registered GP detail. Therefore outcome scores were conducted on the remaining 10 patients VAS for pain has shown significant improvement from an average of 5.4 preoperatively to 1.8 postoperatively ( $p$ value 0.018 ), SF12 has shown significant improvement from 33 to 45.2 following surgery ( $p$ value 0.017 ) which is also in line with the values for the average population of the UK of $50(+/-10)$, DASH score has shown minimal clinical important difference (MCID) in all 10 patients and the overall improvement from 61.1 to 29.8 was significantly different ( $p$ value 0.012 ) Mayo score has shown an average improvement from 39.4 to 57.8 but was not significantly different ( $\mathrm{p}$ value 0.109) (Table 3).

Table 3: Scores ( $\left.{ }^{*} p<0.05\right)$.

\begin{tabular}{|c|c|c|c|c|}
\hline Score & Patients & Preoperative & Postoperative & $\begin{array}{c}\mathbf{p} \\
\text { value* }\end{array}$ \\
\hline SF12 & 10 & 33 & 45.2 & 0.017 \\
\hline (PCS/100) & & $(+/-5.5)$ & $(+/-11.9)$ & \\
\hline DASH & 7 & 59.3 & 15 & 0.012 \\
\hline (MCID=30) & $>$ MCID & & & \\
\hline & 3 & 65.7 & 63.7 & \\
\hline & $<$ MCID & & & \\
\hline MAYO & 10 & 39.4 & 57.8 & 0.109 \\
\hline$(/ 100)$ & & $(+/-13.6)$ & $(+/-23.1)$ & \\
\hline VAS (/10) & 10 & 5.4 & 1.8 & 0.018 \\
\hline & & $(+/-1.5$ & $(+/-1.9)$ & \\
\hline
\end{tabular}

Eight patients approved to undertake the grip and pinch strength tests. Grip strength has shown significant difference between the operated wrist $(20.5 \mathrm{~N})$ and the opposite side $(26.6 \mathrm{~N})$ ( $\mathrm{p}$ value 0.012 ) with no significant difference in pinch strength between both sides $(\mathrm{p}=0.08)$ (Table 4).

Table 4: Results ( $\left.{ }^{*} p<0.05\right)$.

\begin{tabular}{|c|c|c|c|c|}
\hline & $\begin{array}{c}\text { Number of } \\
\text { patients }\end{array}$ & $\begin{array}{c}\text { Affected } \\
\text { side }\end{array}$ & $\begin{array}{c}\text { Normal } \\
\text { side }\end{array}$ & p value* \\
\hline $\begin{array}{c}\text { Grip } \\
\text { strength } \\
\text { (kgs) }\end{array}$ & 8 & 20.5 & 26.6 & 0.012 \\
\hline $\begin{array}{c}\text { (average of } \\
3 \text { trials) }\end{array}$ & 8 & 5 & 6 & 0.08 \\
\hline $\begin{array}{c}\text { Pinch } \\
\text { strength } \\
\text { (kgs) }\end{array}$ & $(+/-10)$ & $(+/-11.4)$ & \\
\hline (three jaw) & & $(+/-2.1)$ & $(+/-2.8)$ & \\
\hline
\end{tabular}

\section{Union at Osteotomy Site and Complications}

All patients achieved full union at the osteotomy site without requiring further surgical interventions. Time to union was 11 weeks on average ranging between nine and 24 
weeks, one patient had delayed union but ultimately achieved radiological and clinical union at 6 months. Average follow up time was 16.5 months ranging between 6 and 45 months, no major complication was encountered, one patient suffered from superficial wound inflammation that was controlled by oral antibiotics and carried on to full union with no further episodes of flare of inflammation, another patient suffered from numbness related to the distribution of the anterior cutaneous nerve of the thigh (graft donor site) which has improved gradually but hasn't fully resolved. All patients reported improved pain and function following the procedure except for one patient who expressed improved pain but had no change in the arc of movement nor had improved function and failed to return to their job prior to the injury.

\section{Discussion}

Deformity resulting from Malunion is not the reason behind addressing such an outcome of distal radial fracture, it is the accompanying pain, loss of function and possible long term implications causing wrist joint, DRUJ and carpal joints disruption. It is rare that such deformities are in one plane, it is not only sagittal or coronal plane deformities that are involved, the deformity involves rotational and axial elements as well. If the deformity exceeds the normal parameters wrist dysfunction is an inevitable outcome. Dorsal angulation per se causes abnormal forces to pass through the radiolunate and ulno carpal articulations [39] dorsal angulation as well as abnormal ulna variance affect the DRUJ inflicting on supination/pronation arc of movement, increasing ulnocarpal impaction and predisposing to degenerative changes involving the TFCC [39].

It is of utter importance to plan for correction of all planes of deformity to restore the normal function of the involved joints. Open wedge osteotomy and dorsal plating have shown to improve radiographic parameters, pain as well as function, an improvement without its own drawbacks with a number of well-documented complications. A study by Keller et al showed that 37 of the 49 patients required plate removal, whilst one of the remaining 12 suffered of rupture of EIP [40], nevertheless they achieved a good function, grip strength and DASH scores. As tendon rupture was argued to be the result of the plate profile, a number of studies using low profile dorsal plate have shown improved function and scores with reduced complications $[41,42]$, nevertheless, dorsal plates have been proven to cause a chronic reactive inflammatory response in a number of animal studies, a response that does decrease with time [43,44].

Closing wedge osteotomy was another means of correcting these deformities in the aim of controlling radial height and ulna variance and at the same time avoid possible complications of delayed union and donor site related issues in open wedge osteotomy with bone grafting. Wada et al compared the outcomes of open wedge versus closed wedge osteotomy of distal radius deformities and concluded that there is a significant difference in arc of movement as well as in average Mayo score in favour of the closing wedge, but showed no significant difference in postoperative radiographic measurements between the two groups, not to mention the need for an additional osteotomy of the ulna for all the patients undergoing closing wedge osteotomy. The patients in the open wedge group [18] had different causes leading to the deformities, were operated by different surgeons, with different approaches and different fixation techniques with or without ulna osteotomy ( 5 of the 18). The author concluded that his study had several limitations that need to be addressed [23].

Volar plates have been used traditionally in correcting deformties with volar angulation [45-47] with good outcomes. Volar locking plates have shown low morbidity with stable mechanical construct in treating distal radial fracture. A handful studies used the volar locking plate in dorsal angulated deformities, Malone et al in 2004 described a technique using a volar fixed angle plate in 4 patients with iliac graft in 2 of them (50\%) [48], Prommesberger et al described a radiovolar approach using a volar fixed angle plate with a different surgical technique to ours [45]. Peterson et al reported 8 patients with dorsal angulation treated with a volar locking plate with follow up of 6 patients only, his surgical technique was slightly different to ours and used corticocancellous bone graft as opposed to cancellous bone graft in our study. all these studies have shown low morbidity related to the use of the volar approach.

To our knowledge this is the largest series of corrective osteotomy for distal radius fracture malunion with more than one plane deformity (11 with dorsal angulation and four with volar angulation) with cancellous bone grafting to be performed consecutively by the same surgeon. The technique described is simple, allows for anatomical correction in all planes, and does not use excessive time or resources. No additional instruments are required, and no additional procedures are expected (compared to ulnar osteotomy for closing wedge procedures, or plate removal in dorsal approach osteotomies). Last but not least it is an easily reproducible technique, with minimal related complications.

Sagittal and coronal plane deformities, as well as axial and rotational plane deformities were all disturbed in most of the cases, hence pre-operative planning, and meticulous plate alignment as described in the surgical technique were of paramount importance in restoring the anatomy of the wrist joint and DRUJ. This was achieved in almost all cases: Volar tilt, ulna variance, radial height and inclination were all restored to normal, which would have a direct effect on the significant improved range of movement and functional outcomes in our series.

All our patients have expressed improved pain and function, except for one patient who in spite of improved pain had no improvement in function and was unable to resume their prior occupation. Wrist joint flexion-extension and supination have all shown significant improvement, and so have pain scores, DASH 


\section{Orthopedics and Rheumatology Open Access Journal}

and SF12 scores, the Mayo score was the only outcome score that showed no significant improvement. Grip strength was significantly weaker on the operated side, whilst pinch strength was regained. All our patients achieved full union without the need for additional procedures. No major complications related to the osteotomy, metalwork or wound was reported in our study.

\section{Conclusion}

In conclusion this technique has proved to be an excellent means of correction of such complex deformity based not only on restoring anatomy based on radiographic measurements, but on improving function proven by improved pain, range of movement and functional outcome scores with minimal morbidity related to the type of osteotomy, metalwork used or approach adopted.

\section{References}

1. Peterson B, Gajendran V, Szabo RM (2008) Corrective Osteotomy for Deformity of the Distal Radius Using a Volar Locking Plate. HAND 3(1): 61-68.

2. Wada T, Tatebe M, Ozasa Y, Osamu Sato O, Sonoda T, et al. (2011) Clinical Outcomes of Corrective Osteotomy for Distal Radial Malunion. A Review of Opening and Closing-Wedge Techniques. The Journal of Bone And Joint Surgery 93(17): 1619-1626.

3. Amadio PC, Botte MJ (1987) Treatment of malunion of the distal radius. Hand Clin 3(4): 541-561.

4. McKay SD, MacDermid JC, Roth JH, Richards RS (2001) Assessment of complications of distal radius fractures and development of a complication checklist. J Hand Surg (Am) 26(5): 916-922.

5. Voche P, Merle M, Dautel G (2001) Non-articular malunions of the distal radius: evaluation and techniques of correction. Rev Chir Orthop Repar Appar Mot 87(3): 263-275.

6. Bushnell BD, Bynum DK (2007) Malunion of the distal radius. J Am Acad Orthop Surg 15(1): 27-40.

7. Jupiter JB (1995) Complex fractures of the distal part of the humerus and associated complications. Instr Course Lect 44: 187-198.

8. Ladd AL, Huene DS (1996) Reconstructive osteotomy for malunion of the distal radius. Clin Orthop Relat Res (327): 158-171.

9. Szabo RM (1993) Extra-articular fractures of the distal radius. Orthop Clin North Am 24(2): 229-237.

10. Szabo RM, Hotchkiss RN, Slater RR Jr (1997) The use of frozenallograft radial head replacement for treatment of established symptomatic proximal translation of the radius: preliminary experience in five cases. J Hand Surg (Am) 22(2): 269-278.

11. Bacorn RW, Kurtzke JF (1953) Colles' fracture; a study of two thousand cases from the New York State Workmen's Compensation Board. J Bone Jt Surg Am 35(3): 643-658.

12. Fernandez DL (1993) Malunion of the distal radius: current approach to management. Instr Course Lect 42: 99-113.

13. Fernandez DL (1988) Radial osteotomy and Bowers arthroplasty for malunited fractures of the distal end of the radius. J Bone Jt Surg Am $70(10):$ 1538-1551.

14. Porter M, Stockley I (1987) Fractures of the distal radius. Intermediate and end results in relation to radiologic parameters. Clin Orthop Relat Res (220): 241-252.
15. Miyake T, Hashizume H, Inoue H, Shi Q, Nagayama N (1994) Malunited Colles' fracture. Analysis of stress distribution. J Hand Surg (Br) 19(6): 737-742.

16. Pogue DJ, Viegas SF, Patterson RM, Peterson PD, Jenkins DK, et al. (1990) Effects of distal radius fracture malunion on wrist joint mechanics. J Hand Surg (Am) 15(5): 721-727.

17. Prommersberger KJ, Lanz U (1999) Biomechanical aspects of malunited distal radius fracture. A review of the literature. Handchir Mikrochir Plast Chir 31(4): 221-226.

18. Werner FW, Glisson RR, Murphy DJ, Palmer AK (1986) Force transmission through the distal radioulnar carpal joint: effect of ulnar lengthening and shortening. Handchir Mikrochir Plast Chir 18(5): $304-$ 308 .

19. Werner FW, Palmer AK, Fortino MD, Short WH (1992) Force transmission through the distal ulna: effect of ulnar variance, lunate fossa angulation, and radial and palmar tilt of the distal radius. J Hand Surg (Am) 17(3): 423-428.

20. Sato S (1995) Load transmission through the wrist joint: a biomechanical study comparing the normal and pathological wrist. Nippon Seikei Geka Gakkai Zasshi 69(7): 470-483.

21. Adams BD (1993) Effects of radial deformity on distal radioulnar joint mechanics. J Hand Surg (Am) 18(3): 492-498.

22. Van Schoonhoven J, Lanz U (2004) Salvage operations and their differential indication for the distal radioulnar joint. Orthopade 33(6): 704-714.

23. Leong NL, Buijze GA, Fu EC, Stockmans F, Jupiter JB (2010) The Distal Radius Malunion (DiRaM) collaborative group. Computer-assisted versus non-computer-assisted preoperative planning of corrective osteotomy for extra-articular distal radius malunions: a randomized controlled trial. BMC Musculoskeletal Disorders 11: 282.

24. Pogue DJ, Viegas SF, Patterson RM, Peterson PD, Jenkins DK, et al. (1990) Effects of distal radius fracture malunion on wrist joint mechanics. J Hand Surg [Am] 15(5): 721-727.

25. Watson HK, Castle TH Jr (1988) Trapezoidal osteotomy of the distal radius for unacceptable articular angulation after Colles' fracture. J Hand Surg [Am] 13(6): 837-843.

26. Bushnell BD, Bynum DK (2007) Malunion of the distal radius. J Am Acad Orthop Surg 15(1): 27-40.

27. Kamath AF, Zurakowski D, Day CS (2006) Low-profile dorsal plating for dorsally angulated distal radius fractures: an outcomes study. J Hand Surg (Am) 31(7): 1061-1067.

28. Villar RN, Marsh D, Rushton N, Greatorex RA (1987) Three years after Colles' fracture. A prospective review. J Bone Joint Surg Br 69(4): 635638.

29. Cooney WP, Dobyns JH, Linscheid RL (1980) Complications of Colles' fractures. J Bone Joint Surg Am 62(4): 613-619.

30. Carter PR, Frederick HA, Laseter GF (1998) Open reduction and internal fixation of unstable distal radius fractures with a low-profile plate: a multicenter study of 73 fractures. J Hand Surg (Am) 23(2): 300-307.

31. Kambouroglou GK, Axelrod TS (1998) Complications of the AO/ASIF titanium distal radius plate system (pi plate) in internal fixation of the distal radius: a brief report. J Hand Surg (Am) 23 (4):737-41.

32. Sanchez T, Jakubietz M, Jakubietz R, Mayer J, Beutel FK, et al. (2004) Complications after Pi Plate osteosynthesis. Plast Reconstr Surg 116(1): 153-158.

33. Flinkkila T, Raatikainen T, Kaarela O, Hamalainen M (2000) Corrective osteotomy for malunion of the distal radius. Arch Orthop Trauma Surg 120: $23-26$. 
34. Krukhaug Y, Hove LM (2007) Corrective osteotomy for malunited extra-articular fractures of the distal radius: a follow-up study of 33 patients. Scand J Plast Reconstr Surg Hand Surg 41(6): 303-309.

35. Jupiter JB, Ring D (1996) A comparison of early and late reconstruction of malunited fractures of the distal end of the radius. J Bone Joint Surg Am 78: 739-748.

36. Ring D, Roberge C, Morgan T, Jupiter JB (2002) Osteotomy for malunited fractures of the distal radius: a comparison of structural and nonstructural autogenous bone grafts. J Hand Surg Am. 2002;27:21622.

37. Orbay J (2005) Volar plate fixation of distal radius fractures. Hand Clin 21(3): 347-354

38. Orbay JL, Badia A, Indriago IR, Infante A, Khouri RK, et al. (2001) The extended flexor carpi radialis approach: a new perspective for the distal radius fracture. Tech Hand Up Extrem Surg 5(4): 204-211.

39. Bushnell BD, Bynum DK (2007) Malunion of the distal radius. J Am Acad Orthop Surg 15(1): 27-40.

40. Keller M, Steiger R (2006) Open reduction and internal fixation of distal radius extension fractures in women over 60 years of age with the dorsal radius plate (pi-plate). Handchir Mikrochir Plast Chir 38(2): 82-89.

41. Kamath AF, Zurakowski D, Day CS (2006) Low-profile dorsal plating for dorsally angulated distal radius fractures: an outcomes study. J Hand Surg (Am) 31(7): 1061-1067.
42. Simic PM, Robison J, Gardner MJ, Gelberman RH, Weiland AJ, et al. (2006) Treatment of distal radius fractures with a low-profile dorsal plating system: an outcomes assessment. J Hand Surg (Am) 31(3): 382 386.

43. Cohen MS, Turner TM, Urban RM (2006) Effects of implant material and plate design on tendon function and morphology. Clin Orthop Relat Res 445: 81-90.

44. Nazzal A, Lozano-Calderon S, Jupiter JB, Rosenzweig JS, Randolph MA, et al. (2006) A histologic analysis of the effects of stainless steel and titanium implants adjacent to tendons: an experimental rabbit study. J Hand Surg (Am) 31(7): 1123-1130.

45. Prommersberger KJ, Moossavi S, Lanz U (1999) Results of corrective osteotomy of malunited extension fractures of the radius at the usual site. Handchir Mikrochir Plast Chir 31(4): 234-240.

46. Shea K, Fernandez DL, Jupiter JB, Martin C Jr (1997) Corrective osteotomy for malunited, volarly displaced fractures of the distal end of the radius. J Bone Jt Surg Am 79(12): 1816-1826.

47. Thivaios GC, McKee MD (2003) Sliding osteotomy for deformity correction following malunion of volarly displaced distal radial fractures. J Orthop Trauma 17(5): 326-333.

48. Malone KJ, Magnell TD, Freeman DC, Boyer MI, Placzek JD (2006) Surgical correction of dorsally angulated distal radius malunions with fixed angle volar plating: a case series. J Hand Surg (Am) 31(3): 366372 .

\section{Your next submission with Juniper Publishers} will reach you the below assets

- Quality Editorial service

- Swift Peer Review

- Reprints availability

- E-prints Service

- Manuscript Podcast for convenient understanding

- Global attainment for your research

- Manuscript accessibility in different formats

( Pdf, E-pub, Full Text, Audio)

- Unceasing customer service

Track the below URL for one-step submission https://juniperpublishers.com/online-submission.php 